\section{Enhanced Cytochemical Detection of Viral Pro- teins and RNAs Using Double-Sided Labeling and Light Microscopy}

BioTechniques 20:111-115 (January 1996)

\begin{abstract}
We have developed a double-sided labeling technique for detecting viral proteins or RNAs in plastic-embedded leaf tissue by immunocytochemistry or in situ hybridization, respectively, and light microscopy. The signal from the target was enhanced by double-sided labeling when compared with single-sided labeling because sections were submerged in labeling solutions with both sides accessible to antibodies or complementary RNAs. The additional label was visible during microscopic analysis. Background signal was decreased since the tissue was probed and washed under conditions where folds and creases in the tissue were minimized. This technique uses the same equipment and chemicals as for single-sided labeling, and thus adjustments for reagent expenditures are not necessary. The procedure should be applicable to animal and plant tissue.
\end{abstract}

\section{INTRODUCTION}

Immunocytochemistry and in situ hybridization (ISH) have been successfully used to determine the location of plant or viral proteins and plant or viral RNAs, respectively, in various plasticembedded plant or animal tissues using light microscopy $(1,4,10,14,16,18)$. Conventionally, sections are analyzed after being mounted on glass slides precoated with an adhesive, such as polyL-lysine or gelatin, and thus are labeled on only one side [i.e., single-sided labeling (SSL)]. This thereby limits the amount of target labeled and the sensitivity of the assay. The target may therefore be difficult to detect when at low levels, such as, during the early stages of viral infection or in tissue infected with a low titer virus. Also, SSL may lead to undesirable background signal due to reagents trapped in bubbles, creases or folds in the attached section. Bubbles, creases or folds can also lead to out-of-focus areas in micrographs. In an effort to improve detection of viral proteins or RNAs in plastic-embedded leaf tissue beyond that achieved with SSL, we have developed double-sided labeling (DSL); a technique not previously reported for use with the light microscope.

\section{MATERIALS AND METHODS}

\section{Plants and Viruses}

Nicotiana tabacum L. cv. Xanthi nn, Nicotiana benthamiana and Arachis hypogaea L. (peanut) cv. Okrun were used as host plants. Purified U1 strain of tobacco mosaic tobamovirus (U1TMV) (12), sunn-hemp mosaic tobamovirus (SHMV; a gift from Dr. C.M. Deom, University of Georgia) and peanut stripe potyvirus (PStV) (3) were used as inocula. Tobacco plants were grown and inoculated as previously described (4). Peanut and N. benthamiana plants were grown in 11- or 16$\mathrm{cm}$ pots, respectively, in a greenhouse. At 4 weeks post-planting, two fully expanded trifoliolate leaves of each peanut plant or two fully expanded leaves of each $N$. benthamiana plant were inoculated with an extract prepared from PStV-infected $N$. benthamiana leaves or from SHMV-infected $N$. benthamiana leaves, respectively. The inoculated plants were then grown as described (4).

\section{Fixation and Embedding}

For detection of TMV and PStV, tissues $(6 \times 3 \mathrm{~mm})$ were randomly sampled from healthy or virus-infected leaves at various days post-inoculation. All tissues were fixed in 3\% paraformaldehyde and $1 \%$ glutaraldehyde in $0.1 \mathrm{M}$ cacodylate buffer, $\mathrm{pH}$ 7.4. PStVor TMV-infected tissue and requisite uninfected control tissue were fixed for $3 \mathrm{~h}$ at $4^{\circ} \mathrm{C}$. SHMV-infected tissue and requisite uninfected control tissue were fixed in a microwave as previously described (4). The fixed tissues were washed 3 times for $15 \mathrm{~min}$ each in 0.1 $M$ cacodylate buffer and partially dehydrated in a graded series of ethanol (30\%, 50\% and 70\%; 30 min each). They were then embedded in LR White resin (London Resin Company, Hampshire, UK) as previously described (4).

\section{Antisera and Biotinylated-RNA Probe}

Polyclonal antiserum against TMV was prepared by injecting a rabbit with purified virus. Polyclonal antiserum against SHMV was a gift from Dr. C.M. Deom and antiserum against PStV was from Dr. D.V.R. Reddy (ICRISAT, Andhra Pradesh, India). All antisera were used without further purification. TMV plus strand-specific, biotinylated-RNA probe, complementary to nucleotides 1-3332 of the TMV genome, was prepared from a cDNA clone of the masked strain of TMV behind an SP6 promoter (7) using the MAXIscript ${ }^{\mathrm{TM}}$ in vitro transcription kit for the synthesis of large quantities of unlabeled RNA as described by the manufacturer (Ambion, Austin, TX, USA) but with the final concentrations of dCTP and biotin-14-CTP (Life Technologies, Gaithersburg, MD, USA) at $0.25 \mathrm{mM}$ and $1.0 \mathrm{mM}$, respectively.

\section{Immunocytochemistry}

Semi-thin $(2 \mu \mathrm{m})$ sections were cut, using glass knives on a Reichert-Jung 2050 microtome (Cambridge Instruments GmbH, Nussloch, Germany) and transferred using small needles onto drops of distilled water (4-5 sections per drop) within wells of 12-well Teflon ${ }^{\circledR}$-coated glass slides (Cel-Line, Newfield, NJ, USA). After removing distilled water under a dissection microscope with a Pasteur pipet drawn out to a point, the sections were allowed to air-dry for approximately $10 \mathrm{~min}$ at room temperature (RT). A drop $(30 \mu \mathrm{L})$ of blocking solution [2\% bovine serum albumin (BSA) and $0.01 \%$ Tween 20 in $0.1 \mathrm{M}$ phosphate buffer, $\mathrm{pH}$ 7.0] was added to each well, and the sections were incubated for $1 \mathrm{~h}$ at $37^{\circ} \mathrm{C}$. During the incubation, sections slowly detached from the glass, and both sides were bathed with the solution. The wells had not been pre-coated with adhesive (e.g., poly-L-lysine), and thus the detachment occurred. The sections remained submerged and in contact with the blocking solution, in part, due to the hydrophilic nature of LR White (13). Access of solutions to both sides of a section attached to a glass slide by means of poly-L-lysine is less likely to occur. All subsequent additions and 


\section{Short Technical Reports}

removals of solutions were done with pointed glass pipets under a dissection microscope to avoid aspirating the sections during manipulations. After the blocking solution was removed, $20 \mu \mathrm{L}$ of antiserum [1:100 dilution of SHMV antibody (Ab), 1:500 dilution of TMV $\mathrm{Ab}$ and 1:1000 dilution of PStV $\mathrm{Ab}$ ] in blocking solution with $1.0 \%$ BSA were added to each well, and the sections were incubated overnight at $4^{\circ} \mathrm{C}$. The antiserum solution was removed, and the sections were washed 5 times by adding, incubating for $5 \mathrm{~min}$ and removing a washing solution $[0.02 \mathrm{M}$ Tris buffer containing $0.5 \mathrm{M} \mathrm{NaCl}$ and $0.01 \%$ Tween 20 (TTBS), $\mathrm{pH} 7.5]$. The sections were incubated in the blocking solution for $30 \mathrm{~min}$ and then for $30 \mathrm{~min}$ in gold-conjugated $(1 \mathrm{~nm})$ goat polyclonal IgG to rabbit IgG (BioCell Research Laboratories, Cardiff, UK) diluted $1: 100$ in $1 \%$ BSA solution $(20 \mu \mathrm{L}$ per well). The sections were washed 5 times in washing solution as described above and were then transferred individually onto drops of distilled water in wells of clean 12-well Teflon-coated slides, washed 5 times in distilled water for 2 min per wash and then incubated in $20 \mu \mathrm{L}$ per well of silver enhancing solution (Aurion, Wageningen, The Netherlands) for 5-10 min in the dark on ice. The sections were washed 5 times in distilled water and then dried individually onto poly-L-lysine-coated glass slides. After counterstaining for approximately $1 \mathrm{~min}$ in $0.01 \%$ toluidine blue, the sections were air-dried, examined and photographed with a Nikon Microphot-FX microscope equipped with a Nikon camera either as bright-field or dark-field images (Nikon, Melville, NY, USA). Through this procedure, folds or creases in the tissue were minimized due mainly to the greatly reduced time of incubation in solutions after attachment to poly-L- lysine-coated slides. Control samples were prepared and analyzed either by labeling sections from the same virusinfected tissues using the SSL technique described previously (4) with virus-specific antibody or by labeling sections from healthy tissues using the DSL technique with virus-specific antibody. Control samples were then incubated with gold-conjugated $(1 \mathrm{~nm})$ goat polyclonal IgG to rabbit IgG and then silver-enhanced as above.

\section{In Situ Hybridization}

Sections were cut, transferred to distilled water and air-dried in wells of Teflon-coated slides as described for the immunocytochemical analyses. As for the immunocytochemical analyses, the sections were not attached to the slide with poly-L-lysine until after the probing and washing steps (see Immunocytochemical section). The sections were covered with prehybridiza- 
tion solution (11) containing $0.01 \%$ Tween $20(20 \mu \mathrm{L}$ per well $)$ and incubated for $1 \mathrm{~h}$ at $42^{\circ} \mathrm{C}$. The prehybridization solution was removed, and the sections were incubated in hybridization solution (ca. 400 ng RNA probe in 1 $\mathrm{mL}$ prehybridization solution, $20 \mu \mathrm{L}$ per well) for $8 \mathrm{~h}$ at $42^{\circ} \mathrm{C}$. The sections were washed 5 times for 5 min each, in TTBS, incubated in the same blocking solution used for the immunocytochemical studies for $30 \mathrm{~min}$, followed by an overnight incubation in a 1:100 dilution of goat anti-biotin IgG (Sigma Chemical, St. Louis, MO, USA) in $1 \%$ (wt/vol) BSA at $4^{\circ} \mathrm{C}$. The sections were washed 5 times as above and incubated in gold-conjugated (1 nm) rabbit polyclonal IgG to goat IgG (BioCell Research Laboratories) diluted 1:100 in a $1 \%$ (wt/vol) BSA solution for $30 \mathrm{~min}$ at

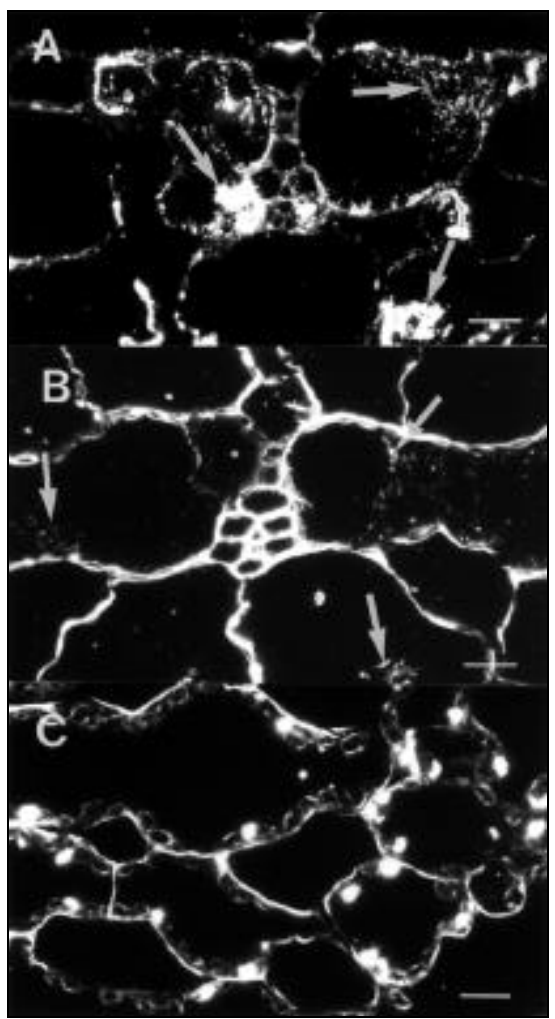

Figure 1. Accumulation of SHMV in cells from inoculated $N$. benthamiana leaf tissue at 14 days post-inoculation. Sections were analyzed for SHMV accumulation by DSL or SSL immunocytochemistry using a polyclonal antibody against SHMV. A) A section analyzed using the DSL technique. B) A section from the same harvested tissue used for (A) and analyzed using the SSL technique. C) A section from healthy $N$. benthamiana leaf tissue analyzed using the DSL technique. Arrows indicate regions with virus accumulation. Bar $=20 \mu \mathrm{m}$.
RT. The sections were then washed, silver-enhanced, washed, dried and counterstained as described for immunocytochemical analysis. Control samples consisted of sections from healthy tissues probed with the biotinylated complementary strand to TMV RNA, TMV-infected tissues probed with a biotinylated 250-bp complementary strand to a mouse $\beta$-actin gene (Ambion), both using the DSL technique, or TMV-infected tissues probed with the biotinylated complementary strand to TMV RNA using the SSL technique. Sections analyzed by SSL were airdried onto poly-L-lysine-coated glass slides. The sections were covered with prehybridization solution $(15 \mu \mathrm{L}$ per section) and incubated for $1 \mathrm{~h}$ at $42^{\circ} \mathrm{C}$. All subsequent steps were similar to those for DSL except that sections were incubated with $150 \mu \mathrm{L}$ of solution per slide instead of $20 \mu \mathrm{L}$ per well as for

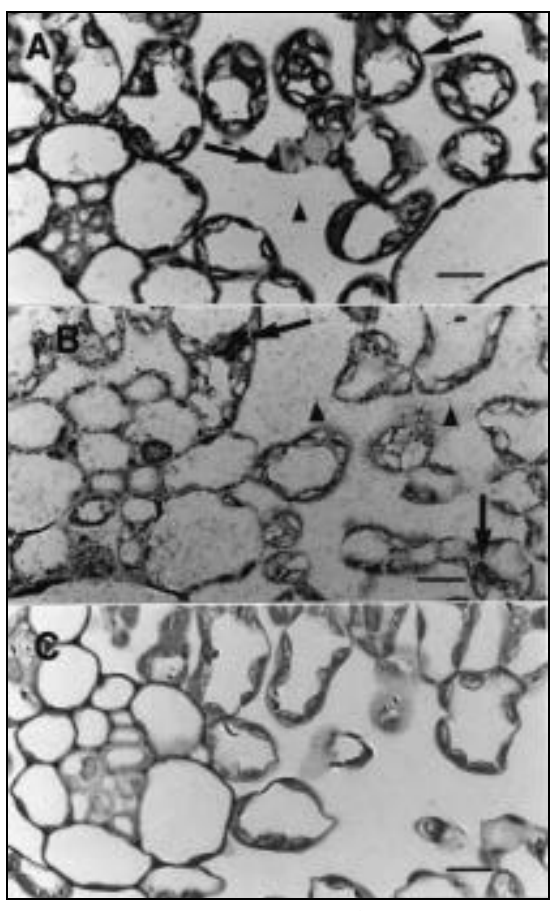

Figure 2. Accumulation of PStV in cells from systematically-infected $A$. hypogaea cv. Okrun leaf tissue at 10 days post-inoculation. Sections were analyzed for PStV accumulation by DSLor SSL-immunocytochemistry using a polyclonal antibody against PStV. A) A section analyzed using the DSL technique. B) A section from the same harvested tissue used for (A) and analyzed using the SSL technique. C) A section from healthy Okrun leaf tissue analyzed using the DSL technique. Arrows indicate regions with virus accumulation, and arrowheads indicate regions with background signal. Bar $=11 \mu \mathrm{m}$. the DSL procedure, and washes were done in a glass staining jar. The SSL procedure was devised to mimick the DSL procedure as closely as possible to allow comparisons.

\section{RESULTS AND DISCUSSION}

\section{Immunocytochemistry}

In early experiments using various viruses and host plants, we found that if a viral protein or RNA did not accumulate to a certain level in cells, either because it was early in the infection cycle or because the virus normally produced low levels of progeny, detection by SSL-immunocytochemistry and light microscopy could be difficult (e.g., Figure 1B). Several techniques, including the use of ultrasmall gold particle probes (8) and epipolarized light

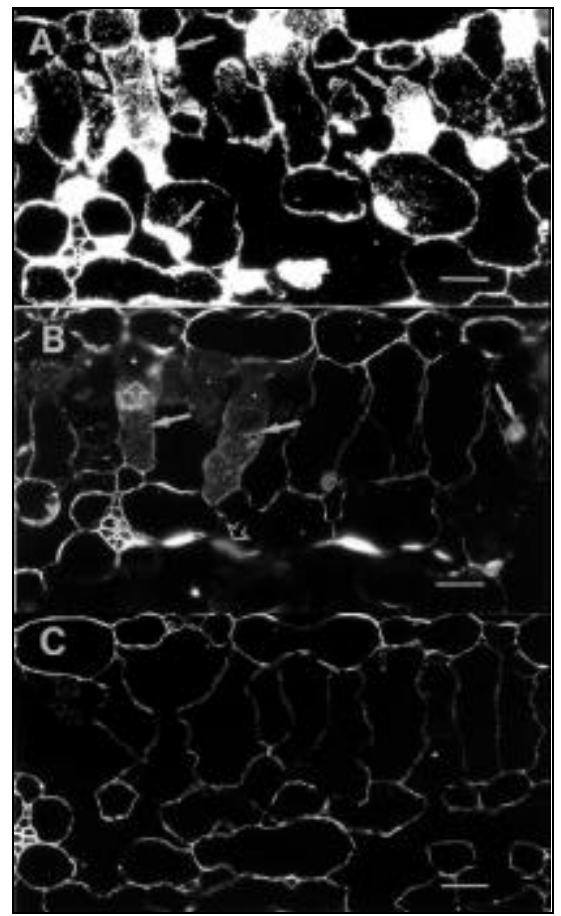

Figure 3. Accumulation of TMV in cells from inoculated $N$. tabacum cv. Xanthi nn leaf tissue at 3 days post-inoculation. Sections were analyzed for TMV accumulation by DSL- or SSLimmunocytochemistry using a polyclonal antibody against TMV. A) A section analyzed using the DSL technique. B) A section from the same harvested tissue used for (A) and analyzed using the SSL technique. C) A section from healthy Xanthi nn leaf tissue analyzed using the DSL technique. Closed arrows indicate regions with virus accumulation. Open arrows indicate folded or creased regions of the section that are out of focus in the micrograph. Bar $=40 \mu \mathrm{m}$. 


\section{Short Technical Reports}

microscopy (5), were used to improve the detection, but the increase in the signal from the target was often accompanied by an increase in background noise (data not shown). SHMV-infected leaf tissue from $N$. benthamiana embedded in LR White resin was used to demonstrate the increase in signal and accuracy obtained using the DSL technique vs. the SSL technique for a low titer virus. Using DSL-immunocytochemistry, much stronger signal was seen in individual cells than that observed using SSL-immunocytochemistry (compare Figure 1, A and B). Similar results were obtained with PStV in $N$. benthamiana (data not shown) or A. hypogaea (Figure 2) and with TMV in N. tabacum (Figure 3). PStV does not accumulate to such high titers as TMV in the respective plants. We also found during SSL-immunocytochemistry that uneven adhesion of a section to the glass slide caused accumulation of labeling reagents in areas between the section and slide and resulted in high background signal (compare Figure 2, A and B). In addition, section folds often occurred during SSL-immunocytochemistry, which resulted in out-of-focus micrographs (compare Figure 3, A and B).

\section{In Situ Hybridization}

ISH is a powerful technique for examining gene expression in individual cells (17). A major problem with ISH is keeping the sections attached to the slide during the hybridization and washing procedures (19). Various slidecoating materials, including $0.01 \%$ poly-L-lysine (Sigma Chemical) (4), Vectabond (Vector Laboratories, Burlingame, CA, USA) (19), 0.4\% Formvar and 3-aminopropyltriethoxysilane (both from Sigma Chemical) (9), have been tried in our previous experiments and none gave $100 \%$ retention of sections on slides (data not shown). Even when using those coating materials that performed best in our studies for tissue retention on slides, folding and creasing of sections were often a problem for the SSL-ISH. In DSL-ISH, viral RNAs are labeled before the sections are attached to the slides, and no section loss occurred during washing steps with this procedure. In addition, the background signal was low because probing and washing took place with sections not attached to a fixed support, thereby avoiding trapping of spurious signal underneath sections. DSL-ISH using TMV-infected tissues probed with biotinylated RNA complementary to TMV RNA gave strong labeling signal compared with SSL-ISH and fewer problems associated with section folding (Figure 4).

DSL has been used for electron microscopic studies $(2,6,15)$ but not for light microscopic studies. The DSL technique developed for light microscopy differs from the procedure for electron microscopy in that the section

\section{WHISPER QUIET VARIABLE SPEED}

MICROCENTRIFUGE

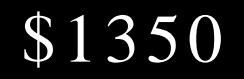

Momentary Switch

4K-14K rpm

$16,000 \times g$ maximum force

13 second acceleration/deceleration

18 place rotor

30 minute timer

RELIABLE SCIENTIFIC

1-800-626-2334

Circle Reader Service No. 196 


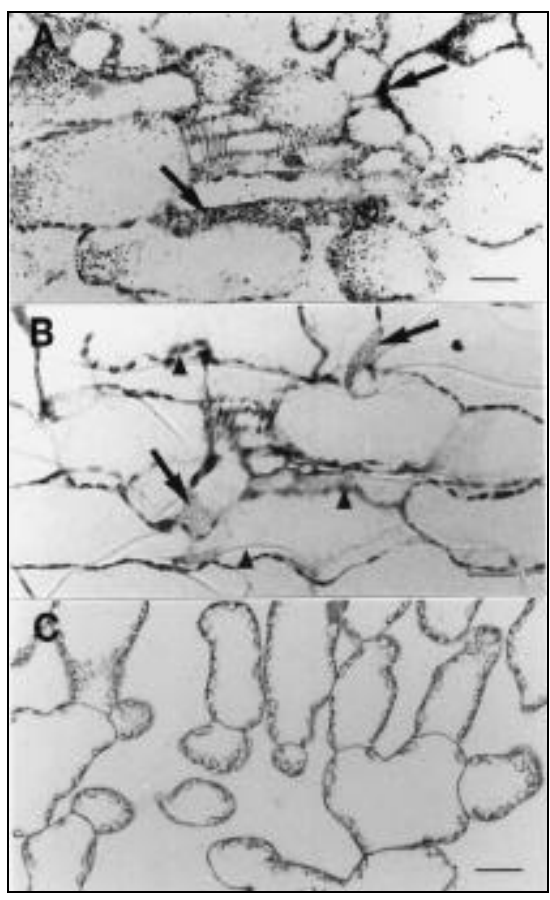

Figure 4. Accumulation of TMV plus strand RNA in cells from inoculated $N$. tabacum cv. Xanthi nn leaf tissue at 3 days post-inoculation. Sections were analyzed for TMV plus strand RNA accumulation by DSL- and SSL-ISH using a biotinylated-RNA probe complementary to nucleotides 1-3332 of the TMV genome. A) A section probed using the DSL technique. B) A section from the same harvested tissue used for (A) above and probed using the SSL technique. C) A section from healthy Xanthi nn leaf tissue probed using the DSL technique. Arrows indicate regions with viral RNA accumulation and arrowheads indicate folded regions that are out of focus. $\mathrm{Bar}=50 \mu \mathrm{m}$.

is not attached to a solid support (i.e., the grid), and both sides of the section are probed at one time rather than sequentially. The DSL-immunocytochemistry and DSL-ISH techniques reported here do not require additional equipment or chemicals and provide more sensitive and accurate results than SSL for routine light microscopic studies. The procedure should be applicable to animal as well as plant tissue.

\section{REFERENCES}

1.Anderson, M.A., G.I. McFadden, R. Bernatzky, A. Atkinson, T. Orpin, H. Dedman, G. Tregear, R. Fernley and A.E. Clarke. 1989. Sequence variability of three alleles of the self-incompatibility gene of Nicotiana alata. Plant Cell 1:483-491

2.Bendayan, M. 1982. Double immunocytochemical labeling applying the protein A-gold technique. J. Histochem. Cytochem. 30:81-85.

3.Cassidy, B., J.L. Sherwood and R.S. Nelson.
1993. Cloning of the capsid protein gene from a blotch isolate of peanut stripe virus. Arch. Virol. 128:287-297.

4.Ding, X.S., M.H. Shintaku, S.A. Arnold and R.S. Nelson. 1995. Accumulation of mild and severe strains of tobacco mosaic virus in minor veins of tobacco. Mol. Plant Microbe Interact. 8:32-40.

5.Gao, K., B.F. Giffin, R.E. Morris, E.L. Cardell and R.R. Cardell. 1994. Optimal visualization of immunogold-silver staining of hepatic PEPCK with epipolarized light microscopy. J. Histochem. Cytochem. 42:823-826.

6.Hills, G.J., K.A. Plaskitt, N.D. Young, D.D. Dunigan, J.W. Watts, T.M.A. Wilson and M. Zaitlin. 1987. Immunogold localization of the intracellular sites of structural and nonstructural tobacco mosaic virus proteins. Virology 161:488-496.

7.Holt, C.A., R.A.J. Hodgson, F.A. Coker, R.N. Beachy and R.S. Nelson. 1990. Characterization of the masked strain of tobacco mosaic virus: identification of the region responsible for symptom attenuation by analysis of an infectious cDNA clone. Mol. Plant Microbe Interact. 3:417-423.

8.Leunissen, J.L.M. and P. van de Plas. 1993. Ultrasmall gold probes and cryoultramicrotomy, p. 327-348. In A.D. Hyatt and B.T. Eaton (Eds.), Immuno-Gold Electron Microscopy in Virus Diagnosis and Research. CRC Press, Boca Raton.

9.Maddox, P.H. and D. Jenkins. 1987. 3Aminopropyltriethoxysilane (APES): a new advance in section adhesion. J. Clin. Pathol. 40:1256-1260.

10.McFadden, G.I., I. Bonig, E.C. Cornish and A.E. Clarke. 1988. A simple fixation and embedding method for use in hybridization histochemistry on plant tissues. Histochem. J. 20:575-586.

11.McQuaid, S. and G.M. Allan. 1992. Detection protocols for biotinylated probes: optimization using multistep techniques. J. Histochem. Cytochem. 40:569-574.

12.Nelson, R.S., G. Li, R.A.J. Hodgson, R.N. Beachy and M.H. Shintaku. 1993. Impeded phloem-dependent accumulation of the masked strain of tobacco mosaic virus. Mol. Plant Microbe Interact. 6:45-54.

13.Newman, G.R. 1989. LR white embedding medium for colloidal gold methods, p. 47-73. In M.A. Hayat (Ed.), Colloidal Gold: Principles, Methods and Applications. Academic Press, New York.

14.Restrepo, M.A., D.D. Freed and J.C. Carrington. 1990. Nuclear transport of plant potyviral proteins. Plant Cell 2:987-998.

15.Slater, M. 1991. Differential silver enhanced double labeling in immunoelectron microscopy. Biotech. Histochem. 66:153-154.

16.Troxler, M., L. Pasamontes, D. Egger and K. Bienz. 1990. In situ hybridization for light and electron microscopy: a comparison of methods for the localization of viral RNA using biotinylated DNA and RNA probes. J. Virol. Methods 30:1-14.

17.VandenBosch, K.A. 1991. Immunogold labelling, p. 181-218. In J.L. Hall and C. Hawes (Eds.), Electron Microscopy of Plant Cells. Academic Press, London.

18.Van Lent, J.W.M. and B.J.M. Verduin.
1987. Detection of viral antigen in semi-thin sections of plant tissue by immunogold-silver staining and light microscopy. Neth. J. Path. 93:261-272.

19.Wilcox, J.N. 1993. Fundamental principles of in situ hybridization. J. Histochem. Cytochem. 41:17 25-1733.

The authors acknowledge Drs. Peter Derrick, Maria Harrison and John Sherwood for comments on the text, Dr. Tim Clark and Loretta DeArton, Stacey Hefner, Blake Hartwell for plant growth and maintenance, and Cuc Ly and Ty Myers for final photographs. Allyson Wilkins is thanked for her typing and proofreading of the manuscript. Address correspondence to Richard S. Nelson, The Samuel Roberts Noble Foundation, Plant Biology Division, P.O. Box 2180, Ardmore, OK 73402, USA. Internet: rsnelson@noble.org

Received 7 February 1995; accepted 1 September 1995.

Xin Shun Ding, Shelly A. Carter and Richard S. Nelson

The Samuel Roberts Noble

Foundation Ardmore, OK, USA 